\title{
MIGRAÇÃO BRASILEIRA NO MERCOSUL
}

\author{
Rogério Haesbaert* \\ Marcelus Silveira**
}

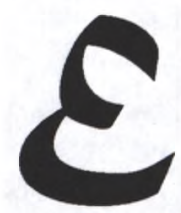

ste trabalho diz respeito ao processo migratório de brasileiros para os demais países do Mercosul, processo antigo, mas que tem se revigorado nas duas últimas décadas, configurando migração diferenciada que envolve principalmente habitantes do Sul do País que se dirigem para os vizinhos do Prata em busca de terras para a agricultura. Ao contrário de outros migrantes que se dirigem predominantemente para as cidades caso dos paraguaios na Argentina - os brasileiros estão, basicamente, expandindo a chamada fronteira agrícola do País e "exportando" os dilemas já vividos no Brasil. Daí, a recente preocupação revelada pela imprensa, especialmente no Uruguai e na Argentina, com a provável entrada dos sem-terras brasileiros em seus territórios.

Trata-se de uma dinâmica que tem profundas implicações econômicas, geopolíticas e culturais, além da questão ecológica, e não podemos menosprezar nenhuma destas dimensões. Assim, nos três vizinhos do Mercosul - Argentina, Uruguai e, mais intensamente, Paraguai -, a presença brasileira tem sido objeto de muita polêmica nas implicações para uma pretensa "soberania nacional" (questão geopolítica), seus efeitos na modernização da agricultura e na alteração do uso do solo (questão econômica), na devastação da cobertura vegetal original (questão ecológica) e na influência e transformação das identidades sociais (questão cultural). Nosso objetivo é mostrar a complexidade deste processo, analisando algumas de suas características básicas, a partir de dados estatísticos e de trabalhos de campo realizados nas áreas de migração brasileira daqueles três países.

\section{RAIZZES HISTÓRICAS E PRO- BLEMÁTICA DA MIGRAÇÃO}

Podemos afirmar que a migração brasileira para os vizinhos do Mercosul começa no final do século XIX e início do século XX, de maneira pontual, com descendentes de alemães fundando colônias no vale do médio rio Paraná, como colônias Hohenau (1898) e Obligado (1912), a nordeste de Encarnación, no Paraguai, e San Carlos (hoje Puerto Rico) e Montecarlo (1919), na província argentina de Misiones. Esta expansão colonial capitalista do Sul do País em direção ao Paraguai e Argentina irá se intensificar a partir dos anos 40 e 50, com a incorporação de terras para a produção de erva-mate. Assim, a companhia brasileira Mate Laranjeiras comprou uma área de $800 \mathrm{mil}$ hectares no leste paraguaio (Kohlhepp, 1982).

Mudanças na divisão internacional do trabalho levaram ao declínio do consumo e produção de erva-mate e nos anos 50 aparece a cafeicultura, também com grandes empresas (e muitos trabalhadores) se estabelecendo em território paraguaio. A Argentina, com legislação mais restritiva à entrada de estrangeiros e clima inadequado para o cultivo do café, acabou até hoje mantendo sua produção de erva-mate, na província de Misiones, praticamente sem a entrada de empresários agrícolas brasileiros.

Nos anos 70, o boom da soja levou tanto grandes capitalistas quanto pequenos produtores brasileiros para o leste paraguaio, fluxo que seria mantido, com idas e vindas, até os anos 90 . A migração para áreas rurais dos vizinhos do Mercosul se completa, na década de 1990 , com a fronteira agrícola do binômio arroz-pecuária expandindo-se do Rio Grande do Sul para o Uruguai e as províncias de Corrientes e Entre Ríos, na Argentina.

As consequências geopolíticas deste movimento tornaram-se mais evidentes por ocasião dos regimes militares, quando a Argentina rivalizava militarmente com 0 Brasil e instituía um plano estratégico de segurança nacional (Plan de Colonización Andresito) para a ocupação da área praticamente despovoada das florestas de Misiones, na fronteira com o Estado do Paraná. No caso do Paraguai, em que a presença brasileira era muito mais ostensiva, os acordos resultantes da construção da barragem de Itaipu eram vistos pela restrita oposição paraguaia (sob o jugo da ditadura de Stroessner) como um processo de (sub)imperialismo. Os incentivos oferecidos pelo governo Stroessner eram muito grandes e muitos migrantes até hoje enaltecem o ditador, pois "era um alemão que chamava os outros", como nos disse um paranaense luterano em Santa Rita (Paraguai). Entre os incentivos, a ausência de imposto sobre a terra vigorou até há três anos. Quanto ao Uruguai, recentes debates na campanha para a presidência da república colocaram a questão do controle da venda de terras para grandes produtores brasileiros.

Em nossa pesquisa de campo ficou visivel a indignação de diferentes classes sociais em relação à presença de brasileiros em seus territórios. Por mais que se diga que a integração no seio do Mercosul é um fato que vem crescendo em diversas esferas da sociedade, no caso da migração, que afeta diretamente o cotidiano das pessoas, esta integração é plena de contradições. Como em todo processo migratório 
Mapa 1

PRINCIPAIS FLUXOS DE BRASILEIROS NOS VIZINHOS DO MERCOSUL

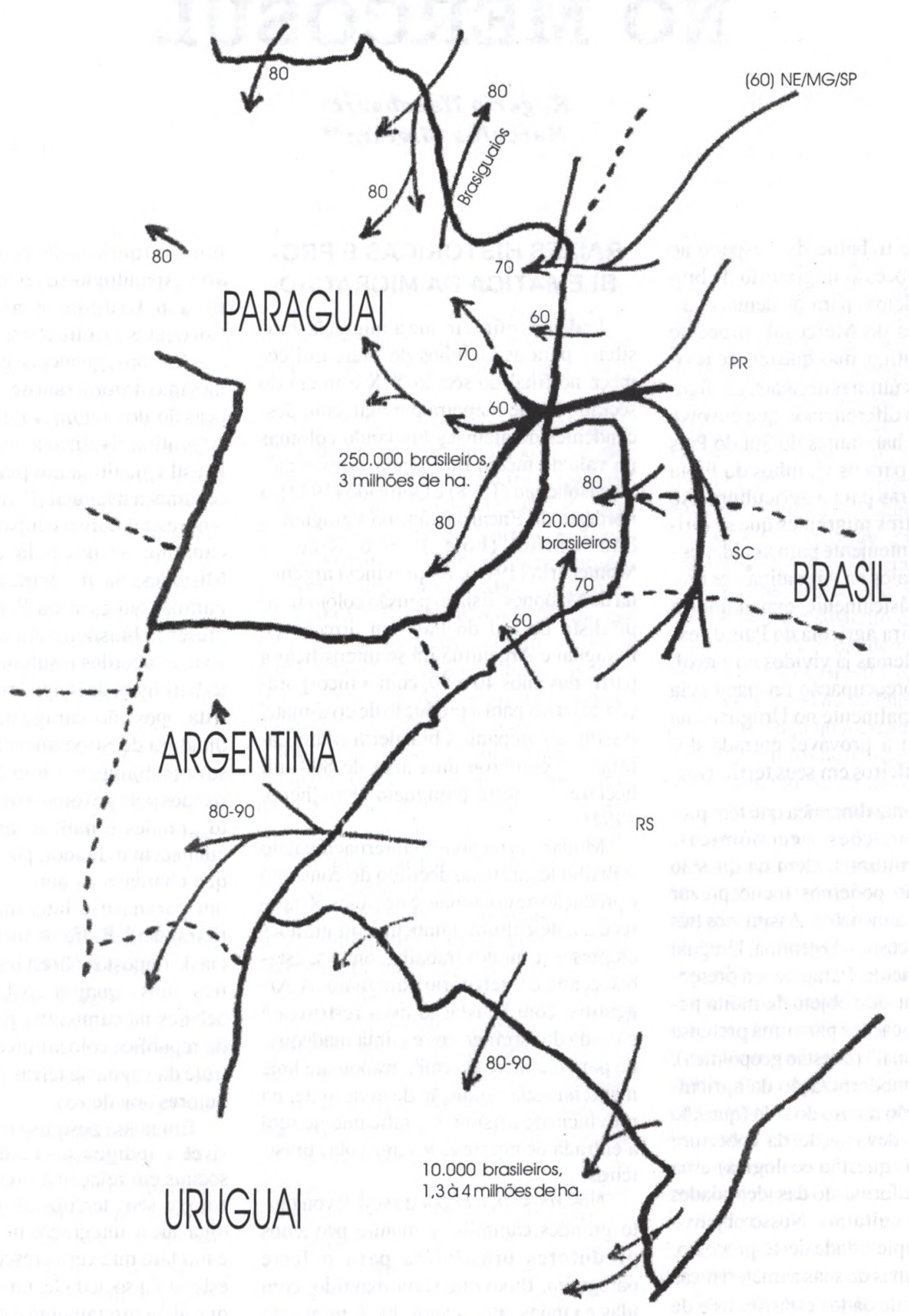

Escala:

Obs: As datas (décadas) e os números sāo aproximados.

6- Travessia /Janeiro - Abril / 99 
internacional, o migrante estrangeiro, mesmo aquele que traz mais contribuições positivas do que negativas para a transformação das áreas onde se instala, é tomado como uma espécie de bode expiatório. Trata-se, como veremos a seguir, de uma dinâmica muito complexa, variável segundo as classes sociais, a intensidade do fluxo, os países e o tipo de atividade aí envolvido.

\section{A QUESTÃO DOS NÚMEROS E A DIVERSIDADE DOS ESPAÇOS DE MIGRAÇÃO}

Uma das questões mais polêmicas no estudo da migração brasileira para os vizinhos do Mercosul é a do número de migrantes. As fontes são muito precárias e a contagem extremamente duvidosa. Basta comparar alguns dados disponiveis em cada país:

Paraguai - os números vão desde 108.526 (Censo Populacional de 1992) até 500.000 brasileiros (Sprandel, 1991); cálculos intermediários citam 250.000 (Folha de São Paulo, 18.8.1996), 325.000 (Veja, 3.4.1996, "Censo dos Brasileiros no Exterior" feito pelo Ministério das Relações Exteriores a partir de dados das embaixadas) e 350.000 (Wagner, 1995, que em outro ponto da mesma obra fala em 450.000 [p.107]). Como se presume que em torno de $50 \%$ dos migrantes são ilegais, com toda certeza os dados censitários são subestimados e seu número mais provável está em torno de 250.000 (vide mapa 1).

Argentina - a antropóloga Gabriela Schiavoni (entrevista, julho de 1997) estima que somente nos departamentos de Guarani e San Pedro (Misiones) vivam em torno de 5.000 brasileiros; a revista Veja (3.4.1996) fala em 16.000 brasileiros na Argentina; para o jornalista Carlos Wagner (1995) são 40.000, e o jornal Folha de São Paulo (7.9.1998) calcula em 100.000 o número de "brasileiros e descendentes de brasileiros" na província de Misiones, onde existiriam cerca de 5.000 famílias brasileiras em situação ilegal. A partir de discussões com pesquisadores locais, estimamos em 20.000 os brasileiros em Misiones.

Uruguai - a presença brasileira é mais importante na ocupação de vasta área de terra do que em relação ao número de migrantes, calculado em 2.000 "produtores de arroz" pela Folha de São Paulo (18.8.1996) e em 15.000 pelo Ministério das Relações Exteriores (Veja, 3.4.1996). É importante, neste caso, como no do Paraguai (onde os brasileiros respondem por cerca de $70 \%$ da produção de soja), atentar para as estimativas de participação na produção agrícola, pois os brasileiros seriam responsáveis por metade da produção uruguaia de arroz e por pelo menos 400.000 toneladas de arroz na Argentina. Estimamos em mais de 10.000 os migrantes brasileiros no Uruguai.

Tanto quanto avaliar o número de migrantes é importante fazer considerações em relação à área em mãos de brasileiros. No Uruguai, embora menos expressivos em número, os brasileiros detêm um percentual de terras muito elevado. Segundo declarações da oposição uruguaia (Frente Amplia), em 1994 os brasileiros ocupavam um quarto das terras produtivas do país, em torno de 4 milhões de hectares. Dados oficiais do governo uruguaio indicam que $10 \%$ dos 13 milhões de hectares agricultáveis do Uruguai estão em mãos de brasileiros (Benetti, 1994).

No Paraguai a densidade de brasileiros e o número de propriedades continuam extremamente concentrados nos departamentos mais orientais, especialmente Alto Paraná e Canindeyú. Aí há nítida diferença entre o norte (Canindeyú), muito mais pobre, e o sul, onde estão os mais ricos plantadores de soja. Em Santa Rita, a sudoeste de Ciudad del Este, segundo o Prefeito Concepción Rodriguez, cerca de $80 \%$ da população é brasileira. A cidade é vista pela prefeitura como "o maior pólo de desenvolvimento" do Paraguai, contando com sete agências bancárias e cinco emissoras de rádio. Embora predominem migrantes do Sul do Brasil, em Canindeyú e Amambay encontram-se muitos matogrossenses, mineiros, paulistas e nordestinos. Mesmo em Santa Rosa, "capital da soja", colonizada basicamente por descendentes de alemães do planalto gaúcho, encontramos migrantes mineiros extremamente pobres, vindos do Vale do Jequitinhonha e moradores do bairro mais pobre da cidade, sugestivamente denominado Vila Guarani (sem guaranis).

Recentemente, nos anos 90, começou novo fluxo, ainda pouco expressivo, mas que deve crescer, especialmente de grandes proprietários para a área do Chaco, na metade oeste do Paraguai (vide mapa 2), incluindo a fronteira com a Bolívia e Argentina. Fazendeiros de gado e soja do Mato Grosso do Sul e alguns que já estavam no leste do Paraguai estão se dirigindo para aquela região. Ocorre também migração de brasileiros pobres que trabalhavam para os colonos menonitas em Caaguazú, no centro-leste, para a colônia menonita de Filadélfia, no Chaco.

\section{O CASO URUGUAIO}

O Uruguai, com uma fronteira em grande parte "seca" com o Brasil, sempre teve grandes latifúndios pecuaristas em mãos de brasileiros, que muitas vezes faziam de suas propriedades simples extensão comum dos dois lados da fronteira. Mais recentemente, com a entrada da rizicultura na Campanha Gaúcha e com os preços da terra muito mais baixos no Uruguai, houve rápida expansão desses produtores de arroz para o interior uruguaio, processo semelhante àquele que ocorre nas províncias argentinas de Corrientes e Entre Ríos. Hoje, com a valorização da terra, a migração diminui, embora o menor custo de vida e a "tranquilidad" continuem sendo fatores de atração. Além disso, como no Paraguai, foi possível constatar que muitas terras foram compradas num processo de "lavagem do dinheiro sujo" obtido nos circuitos ilegais da economia, como o narcotráfico. Tivemos conhecimento de brasileiros que chegam com "dinheiro vivo" e a única coisa que pedem é para que ninguém fique sabendo do negócio no Brasil.

Além dos grandes produtores migram também, às vezes em condição de total ilegalidade, trabalhadores brasileiros, considerados até por alguns produtores uruguaios como "mais trabalhadores", por serem "descendentes de italianos e alemães" e estarem mais habituados a maior disciplina exigida pela agricultura em relação à pecuária. São raros os trabalhadores uruguaios nas lavouras de arroz: "uruguaio não trabalha, só com gado, que não é trabalho... bota um trabalhador para 1000 ha. de pecuária e já está bom. Brasileiro é muito mais trabalhador", disse-nos um 
Mapa 2

\section{PRESENCA DE MIGRANTES BRASILEIROS NO PARAGUAI}

BOLIVIA

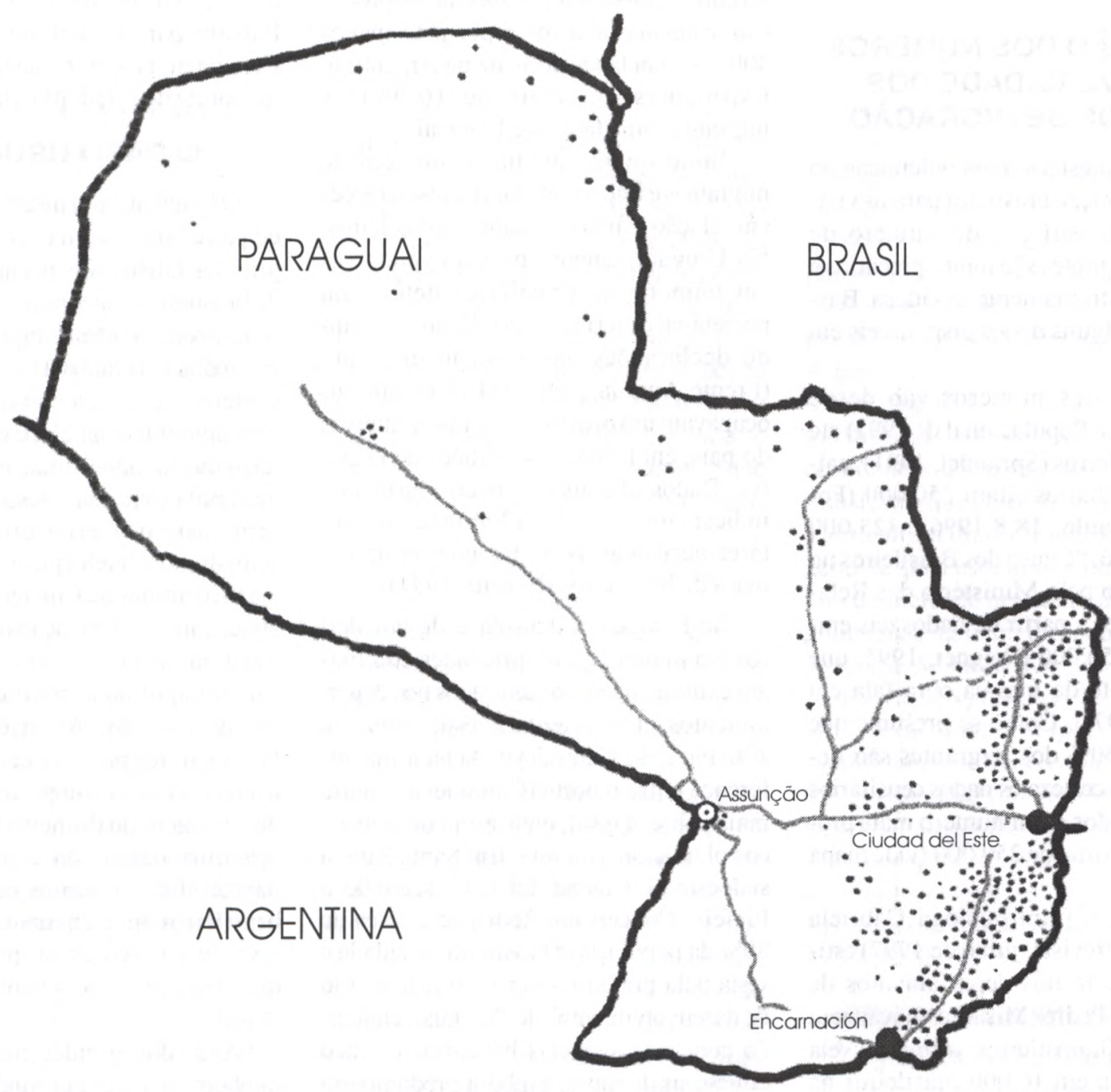

Escala:

$0 \quad 168 \mathrm{Km}$

LEGENDA:

$\odot \odot$ PRINCIPAIS CIDADES

PRINCIPAIS RODOVIAS ASFALTADAS

$\because$ ÁREAS DE MIGRAÇÃO BRASILEIRA 
agrônomo uruguaio de Melo. Por outro lado, numa visão preconceituosa, um arrendatário uruguaio afirmou que "basta ir a uma cidade do interior do Rio Grande do Sul que há uma 'negrada' esperando para arrumar emprego", "o Brasil tem aquela negrada toda que quer vir trabalhar".

Como o controle em vários pontos da fronteira é praticamente nulo, esses migrantes chegam sem nenhum amparo legal, proliferando hoje as questões trabalhistas envolvendo proprietários que muitas vezes deixam de pagar seus trabalhadores. Atualmente, há também migrantes que trabalham em alguns setores de serviços, desde a construção civil até serviços religiosos, notando-se, como no Paraguai, um aumento expressivo de igrejas pentecostais trazidas por brasileiros, como a Assembléia de Deus.

Outra influência brasileira no Uruguai, que tem longa data, mas que vem se intensificando, são as alterações do espanhol, "carimbado" pelo português, que é a expressão local para este "portuñol" fronteiriço. Visitamos uma vila no interior do departamento de Tacuarembo em que a maioria dos habitantes era brasileira e a televisão exibia programas da Rede Globo.

Um senhor, idoso, com quem viajamos, reclamou indignado que os brasileiros ricos mantêm suas propriedades principais no Brasil, mas estão invadindo o país, comprando as melhores terras (enumerou algumas estâncias famosas), "una barbaridad", e se pergunta se vai acontecer ali o mesmo que aconteceu em Jaguarão, onde o Brasil conquistou uma parte da Lagoa Mirim no início do século.

\section{O CASO ARGENTINO}

$\mathrm{Na}$ Argentina temos duas áreas rurais históricas e geograficamente distintas em termos de migração brasileira. Uma, mais antiga (com fluxo importante desde os anos $60)$, a nordeste, na província de Misiones, envolve a expansão da fronteira agrícola brasileira de pequenos agricultores expulsos pela intensa divisão e/ou concentração da terra no Sul do país; outra, mais recente (a partir do final dos anos 80, principalmente), relaciona-se à expansão capitalista de grande produtores de arroz para terras mais baratas e de qualidade superior, em províncias como Corrientes e Entre Ríos.

No primeiro caso, o número de brasileiros é muito maior, mas no segundo a área ocupada é muito mais expressiva. Nas florestas de Misiones, em busca de terra barata e mais fértil (ainda por desmatar), os pequenos produtores do Rio Grande do Sul se estabeleceram em colônias como a Alícia e a Aurora, junto ao rio Uruguai, expandindo-se depois em direção ao interior em localidades hoje mais dinâmicas, como San Vicente e San Pedro. A atividade agrícola predominante, inicialmente, foi o fumo e as essências (menta, citronela), intercaladas pela soja, durante os anos 70 . Hoje a economia agrícola é um pouco mais diversificada, e há brasileiros que conseguiram alguma ascensão social e estão investindo em setores como o de restaurantes e hotelaria. Há também alguns profissionais liberais e muitos trabalhadores no setor madeireiro. Um dos atrativos é o salário mínimo, mais do que o dobro do brasileiro. As privatizações e o desemprego, contudo, também têm afetado muito a situação social na província de Misiones.

Aqui, tal como no Paraguai, muitos brasileiros vivem ilegalmente e são "arregimentados" por políticos nos períodos de eleições para votarem no Brasil. Para muitas famílias ilegais (que entraram pelo "porto capivara", como dizem os argentinos), precariamente instaladas e escondidas "no meio do mato", é o único momento em que percebem que são "úteis" e que têm interesse para o Estado. Ou seja, só valem como um número representado pelo voto em época de eleição.

No caso da migração brasileira para o Pampa úmido de Corrientes e Entre Ríos, com alguns brasileiros passando também para a outra margem do rio Paraná, em Formosa, trata-se de grandes empresários em busca de terras baratas para o binômio pecuária-arroz, sendo que alguns começam a ingressar também no setor madeireiro, com o cultivo principalmente de eucaliptos em áreas de campo.

Os vínculos destes brasileiros, especialmente os de Misiones, com o território brasileiro, são muito evidentes, dando origem a conexões entre os dois lados da fronteira que podemos denominar de redes transfronteiriças. Foi possível identificar algumas destas redes:

- economicamente, muitos brasileiros mantêm sua nacionalidade para fazer uso de benefícios no Brasil, como financiamentos do Banco do Brasil e aposentadoria rural; alguns agricultores beneficiam o fumo no Brasil.

- no setor de serviços são muito utilizados os do Brasil pois, além da identificação dos usuários, as cidades mais importantes ao longo da fronteira quase sempre estão do lado brasileiro; há um intenso comércio ilegal feito por brasileiros na Argentina, e que liga, por exemplo, a "zona franca" de Encarnación com cidades do norte do Rio Grande do Sul.

- culturalmente, muitos laços de parentesco são mantidos, e colônias como Aurora e Alícia, ao longo do rio Uruguai, são praticamente extensão do território brasileiro em termos culturais (utilizam a língua portuguesa, torcem "pelo Inter ou pelo Grêmio", ouvem músicas gaúchas, assistem programas de televisão brasileiros).

Independente dos processos migratórios é interessante lembrar também as iniciativas de integração via Mercosul ou estimuladas por ele, que começam a estruturar algumas redes transfronteiriças em um nível mais amplo, como as reuniões de prefeitos do Sul do Brasil, de algumas províncias argentinas e do Paraguai, o "primeiro roteiro turístico do Mercosul" integrando as missões do Rio Grande do Sul, Misiones e sul do Paraguai, e acordos entre universidades gaúchas, catarinenses e argentinas.

\section{O CASO PARAGUAIO}

O caso paraguaio é o mais destacado, onde a migração se dá há muito mais tempo e com muito maior intensidade, envolvendo número muito maior de migrantes pobres. Como era uma área de matas e os brasileiros foram responsáveis pela sua devastação, "expulsando" muitos descendentes de guaranis para o centro-leste do país ou para a periferia pobre de cidades como Ciudad del Este (hoje numa conurbação de mais de 250 mil habitantes), formaram-se quase "territórios brasileiros" dentro do Paraguai, onde já há inclusive prefeito brasileiro (em San Alberto). Entre as características "brasileiras" mantidas pelos migrantes dentro do 
território paraguaio podemos destacar:

- o uso do real e, em muitos lugares, os preços "abrasileirados";

- a obtenção de financiamentos via Banco do Brasil (para muitos no próprio Brasil, já que mantêm a nacionalidade brasileira);

- a utilização da língua portuguesa como primeiro idioma de comunicação, incluindo vários programas de rádio em português;

- a manutenção do título eleitoral no Brasil, não se vinculando, por vários motivos, à cidadania paraguaia;

- presença expressiva de padres, médicos e outros profissionais liberais brasileiros;

- criação de Centros de Tradições Gaúchas em pelo menos duas cidades.

Estas e outras características permitem afirmar que existem várias redes mantidas entre os migrantes e o Brasil, entre elas o intenso comércio, a obtenção de financiamentos junto a bancos no Brasil, a utilização de serviços no Brasil (hospitais em Foz do Iguaçu e Guaíra), os laços culturais (o CTG de Santa Rita, por exemplo, está vinculado à Região Tradicionalista de Guarapuava, no Paraná, a influência das emissoras de rádio e televisão brasileiras é enorme) e até mesmo, como vimos, os vínculos político-eleitorais, com vereadores de algumas cidades brasileiras se elegendo graças aos votos dos brasileiros no Paraguai e na Argentina.

Entre alguns exemplos de iniciativas para exercer maior controle ou para se contrapor à presença brasileira no Paraguai, ainda que muito variáveis em termos da intensidade e do período em que ocorrem, temos a criação de vários entraves burocráticos (a nova lei de imigração de 1996 exige atestado de boa conduta) e em termos de taxas (às vezes cobradas várias vezes) para a legalização dos migrantes; a cobrança de "pedágios" (ilegais) nas estradas pela polícia para brasileiros sem documentos; algumas prisões arbitrárias para sem documentos ou menores; restrições à elegibilidade de brasileiros para cargos públicos e obrigatoriedade do espanhol e do guarani em todas as escolas de ensino básico. Segundo o prefeito de Santa Rita, "a la gente muy pobre no les gusta que los brasileños estean en la polí- tica". Apesar de cerca de $80 \%$ da população do município ser brasileira, somente 4 dos 12 "consejales" (vereadores) são brasileiros.

Um dos traços dos brasileiros mais criticados tanto por argentinos quanto por paraguaios é o cuidado com a terra, a questão ecológica. Segundo os prefeitos de Santa Rita e Santa Rosa, que entrevistamos, os paraguaios têm maior consciência ecológica. Para o prefeito de Santa Rosa os brasileiros devastaram em dez anos o que não se devastou em toda a história da região. Não há respeito pelos $20 \%$ de preservação da mata que a lei exige e há séria contaminação da água dos rios, principalmente por agrotóxicos utilizados na agricultura. Na Argentina, que ainda tem uma área muito grande de matas nativas em Misiones, os colonos brasileiros frequentemente são acusados de contrabandear madeira para o Brasil. Em vários pontos da fronteira e observando-se imagens de satélite é gritante o contraste entre o lado argentino, ainda coberto de mata, e o lado brasileiro, completamente desmatado.

É interessante ressaltar que estes fluxos migratórios no interior do Mercosul são muito dinâmicos. Alguns, atrelados a fatores instáveis capazes de alterar em pouco tempo a margem de lucro dos capitalistas ou aumentando o desemprego, ora estancam, ora são retomados com novo ímpeto. Muitos são também os migrantes que fazem destas áreas simples etapas ou escalas dentro de um circuito muito mais amplo em busca de ascenção social que acaba nunca se realizando.

Muitas cidades do Paraná, inclusive a periferia de Curitiba, têm recebido "brasiguaios" que retornam esperando algum apoio, especialmente do Estado. Em favelas de Foz do Iguaçu conhecemos familias que foram expulsas por grandes proprietários brasileiros no Paraguai. Em trajetos bem diferentes, tomamos conhecimento de famílias gaúchas que vieram de Barreiras, na Bahia, para o Paraguai, e acabaram voltando para o Brasil, famílias catarinenses que vieram do Mato Grosso para o Uruguai e famílias paranaenses provenientes de Santa Cruz de la Sierra, na Bolívia, para o Chaco paraguaio. São trajetos às vezes tão inusitados que surpreendem, revelando o grau da mobilidade geo- gráfica (raramente social) alcançada por estes migrantes muito além das fronteiras do Sul do Brasil e dos vizinhos do Mercosul.

A intensidade, as contradições e a complexidade deste processo migratório, envolvendo tantas classes sociais, identidades culturais, interesses econômicos e geopolíticos, levam-nos à questão da relevância e mesmo da urgência em se discutir uma legislação migratória comum, muito mais solidária e democrática no interior do Mercosul

*Rogério Haesbaert é Prof. de Geografia da UFFNiterói(RJ) e Pesquisador do CNPq.

* "Marcelus Silveira é Prof. de Geografia e foi bolsista do PIBIC/CNPq neste projeto. Também participam da pesquisa os bolsistas Mercelo Santa Bárbara e Luiza da Costa Leite.

(Os pesquisadores agradecem o apoio da Pastoral do Migrante da Igreja Católica durante o trabalho de campo no Paraguai).

\section{BIBLIOGRAFIA}

BENETTI, M.

(1994) "Argentina e Uruguai: a nova fronteira agricola sul-riograndense". Indicadores Económicos FEE. Porto Alegre, n. 22, vol. 2, pp. 217-235.

KOHLHEPP, G.

(1982) Problems of dependent regional development in Eastern Paraguay with special reference to brazilian influence in the pioneer zone of the Amambay plateau. Applied Geography and Development, n. 22, Tübingen.

OVIEDO, A. e GORTARI, J.

(1997) Misiones en el intercambio económico regional y en el contexto del Mercosur. Estudos Regionales 10.

Paraguai. Censo Nacional de Población y Viviendas. Año 1992. Dirección Nacional de Estadisticas y Censos, Assunção, 1994.

Paraguai. Colonias privadas habilitadas. Instituto del Bienestar Rural, Unidad de Estadistica. Assunção, 1996.

SCHIAVONI, G.

(1995) Colonos y ocupantes: parentesco. reciprocidad y diferenciación social en la frontera agraria de Misiones. Posadas, Editorial Universitaria (UNAM)

SPRANDEL, $M$

(1991) Brasiguaios: conflito e identidade em fronteiras internacionais. Dissertação de mestrado. Rio de Janeiro, Museu Nacional, UFRJ.

WAGNER, C.

(1995) O Brasil de bombachas Porto Alegre, L\&PM.

Jornais:

Folha de São Paulo (São Paulo, 18/8/1996, pp. 21,2-14 e 2-15 e 7/9/1998, pp.1-5); Jornal do Brasil (Rio de Janeiro, 21/8/1994, p.16); vários números de Mate Amargo (Montevideo), ABC Color (Assunção) e El Territorio (Posadas).

Revista Veja, 3/4/1996. 